\title{
AUTONOMIA DAS PESSOAS TRANSEXUAIS E CIDADANIA: UMA DEFESA À POSSIBILIDADE DE ALTERAÇÃO DO REGISTRO CIVIL INDEPENDENTEMENTE DE AUTORIZAÇÃO JUDICIAL
}

\author{
THE AUTONOMY OF TRANSGENDER PEOPLE AND CITIZENSHIP: A \\ DEFENSE TO THE POSSIBILITY OF CHANGING CIVIL REGISTRY \\ REGARDLESS OF JUDICIAL AUTHORIZATION
}

\section{${ }^{1}$ Roberta Lemos Lussac}

\begin{abstract}
RESUMO
O presente trabalho pretende demonstrar a íntima relação existente entre o direito à inclusão do nome social no registro civil das pessoas transexuais e o exercício pleno da cidadania e, a partir desta ideia, defender a possibilidade de alteração do registro civil para inclusão do nome social sem necessidade de determinação judicial. Para tanto, imprescindível defender a despatologização da transexualidade a fim de que as pessoas transexuais saiam da margem da sociedade e assumam o protagonismo de sua própria existência.
\end{abstract}

Palavras-chave: Nome social, Registro civil, Pessoas transexuais, Cidadania

\begin{abstract}
This paper aims to demonstrate the close relationship between the right to inclusion of social name in the civil registry of transgender people and the full exercise of citizenship, and from this idea, defending the possibility of changing the civil registry to include the social name without need for judicial determination. Therefore, it is essential to defend depathologization of transsexuality so that transgender people be able to leave the margins of society and assume the role of their own existence.
\end{abstract}

Keywords: Social name, Civil registry, Transgender people, Citizenship

\footnotetext{
${ }^{1}$ Mestre em Direito Público e Evolucão Social pela Universidade Estácio de Sá -UNESA. Rio de ianeiro. Professora pela Universidade Veiga de Almeida -UVA, Rio de Janeiro, (Brasil) Email: tutortreinamento@ gmail.com
} 


\section{DIREITO À INCLUSÃO DO NOME SOCIAL NO REGISTRO CIVIL E CIDADANIA: UMA RELAÇÃO SIMBIÓTICA}

O direito à inclusão do nome social no registro civil das pessoas transexuais e o exercício pleno da cidadania encontram-se necessariamente relacionados, na medida em que é impossível imaginar que uma pessoa consiga vivenciar plenamente seu status de cidadã se o nome e o sexo que esta ostenta em sua documentação divergem da imagem que esta apresenta em sociedade. , se o direito ao nome é direito fundamental e se o prenome, a despeito de sua definitividade, pode ser substituído por apelidos públicos notórios, como autoriza o artigo 58 da Lei de Registros Públicos, não há razão para submeter eventual alteração à autorzaçãa judicial. Submeter o gozo de um direito fundamental à discricionariedade judicial constitui, essencialmente, um esvaziamento de sua fundamentalidade, posto que o exercício do referido direito pode ou não ser autorizado. Assim busca-se demonstrar que por ser o nome elemento caracterizador e individualizador da pessoa humana, exercendo papel fundamental em sua vida, tanto na dimensão privada quanto na pública, e apresentando, portanto, uma relação simbiótica com o próprio exercício da cidadania, não se sustenta, com base em um exercício hermenêutico que tem por fundamento maior a dignidade da pessoa humana, qualquer exigência legal de autorização judicial para adequação do nome civil ao nome social.

\subsection{TRANSEXUALIDADE: A IMPORTÂNCIA DA DESPATOLOGIZAÇÃO.}

Para a compreensão da transexualidade, faz-se necessária uma curta digressão histórica. O termo transexualidade surge no ano de 1910 quando, para se referir a transexuais fetichistas $^{1}$, o sexólogo Magnus Hirschfeld (CASTEL, 2001) utilizou o termo "transexualpsíquico". O termo voltou a ser utilizado em 1949, quando David Cauldwell (EKINS, 2001) publicou um estudo de caso a respeito de um transexual que queria se masculinizar. Para Cauldwell, transexual seria o indivíduo que apresenta desconforto com o seu sexo de origem, objetivando a transformação de seu corpo de acordo com o seu desejo de viver como se pertencesse ao sexo oposto.

$\mathrm{Na}$ década de 50 do século XX, surge o conceito de transexualismo após as primeiras cirurgias de redesignação sexual através da retirada do pênis, termo forjado pelo médico norte-americano Harry Benjamin que designava uma patologia relativa à identidade sexual. Na década de 60, nos Estados Unidos, em razão de uma série de desdobramentos práticos

\footnotetext{
${ }^{1} \mathrm{O}$ travestismo fetichista caracteriza-se pel o a to de vestir roupas do sexo oposto, principalmente com o objetivo de obter excitação sexual e de criar a aparência de pessoa do sexo oposto.
} 
referentes à transexualidade, esta passa a ser considerado "disforia de gênero", termo utilizado por John Money (CASTEL, 2001).

A utilização do termo "gênero", por John Money, apresenta enorme relevância em posteriores considerações a respeito da condição de transexual, na medida em que designa certa plasticidade da sexualidade, defendendo a independência radical entre o social e o biológico.

Em 1973, com o objetivo de inserir as pessoas transexuais em processos terapêuticos formais, com base nas definições de Harry Benjamin, Norman Fisk criou uma nomenclatura própria das doenças psiquiátricas para o transexualismo, baseada fundamentalmente no autodiagnostico. Em 1977, esta condição foi incorporada à categoria de "disforia de gênero". Em 1980, a condição transexual foi agregada ao Manual de Diagnóstico Psiquiátrico, DSM II (Manual Diagnóstico e Estatístico das Desordens Mentais) e, em 1994, com a publicação do DSM IV, o termo "transexualismo" foi substituído por "transtorno de identidade de gênero", indicativo da patologização da condição de transexual, sob o ponto de vista biomédico (CASSEMIRO). Com base no DSM IV e a depender da idade, aqueles com uma forte e persistente identificação com o sexo oposto e um persistente incômodo com seu sexo ou um sentimento de impropriedade dos papéis de gênero desse sexo passaram a ser diagnosticados como Transtorno de Identidade de Gênero na Infância (302.6), Adolescência e Adulto (302.85).

Esta patologização é um desafio que as pessoas transexuais enfrentam diuturnamente, sendo grave fonte de preconceito, dificultando sua inserção social e profissional.

Berenice Bento e Larissa Pelúcio (BENTO; PELÚCIO) criticam:

A patologização da sexualidade continua operando com grande força, não mais como "perversões sexuais" ou "homossexualismo", mas como "transtornos de gênero". Se o gênero só consegue sua inteligibilidade quando referido à diferença sexual e à complementaridade dos sexos, quando se produz no menino a masculinidade e na menina a feminilidade, a heterossexualidade está inserida aí como condição para dar vida e sentido aos gêneros.

A despeito da presença da transexualidade no Manual Diagnóstico e Estatístico das Desordens Mentais, há uma forte resistência contra a patologização, com adesões de pessoas 
em vários países ao movimento Pare a Patologização! Desde o ano de 2010, a campanha vem ganhando adeptos no Brasil e, apesar do receio de alguns ativistas quanto à perda do acesso gratuito ao processo transexualizador, oferecido pelo Sistema Único de Saúde, Bento e Pelício (BENTO; PELÚCIO) entendem que "a patologização não garantiu direitos de fato, mas impôs um modelo para se pensar a transexualidade como experiência catalogável, curável e passível de normalização".

\subsection{GÊNERO: UMA PERFORMATIVIDADE ASSUMIDA PELO INDIVÍDUO}

De toda forma, a racionalidade que fundamenta o termo transexualidade baseia-se no desacordo patológico entre sexo e gênero, e pressupõe que, por um lado, o sexo é determinista, sendo definido pela natureza e externado pelo corpo orgânico, biológico e genético, representando uma categoria que ilustra a diferenciação biológica entre homens e mulheres, e, por outro hdo, o gênero é construtivista, na medida em que é considerado uma construção histórica e social (ARAN, 2006).

Essa racionalidade, que se apresenta, ao mesmo tempo, determinista e construtivista, domina as bases do estudo do fenômeno da transexualidade, a despeito de restringir sobremaneira as infinitas possibilidades de manifestação das subjetividades e das sexualidades. Por esta razão, autores como Michel Foucault e Judith Butler problematżam este tipo de raciocínio.

Foucault (FOUCAULT, 2015, pp. 07-18) defende que o sexo é o resultado complexo de uma experiência histórica singular e não uma invariante, um dado natural passível de diversas manifestações. Para se falar de sexo, faz-se necessário considerar a produção dos saberes que o constituem, os sistemas de poder que regulam suas práticas e as formas por meio das quais os indivíduos podem e devem se identificar como sujeitos sexuados. Judith Butler (BUTLER, 2002, p.18), por sua vez, defende que sexo - homem e mulher - não é uma condição estática e sim "uma construção ideal forçosamente materializada através do tempo.".

Há tempos, as teorias biológicas da sexualidade e as condições jurídicas impostas aos indivíduos guiaram a sociedade e o Estado à contestação da possibilidade de sexo e gênero dissonantes em um só corpo (FOUCAULT, 2015, p 116). Márcia Áran (ÁRAN, 2006) esclarece que "o dispositivo de poder instaurou a necessidade de saber por meio da medicina qual o sexo determinado pela natureza e, por consequência, aquele que a justiça exige e reconhece." 
Butler (BUTLER, 2003, p. 18) também questiona a concepção de gênero amplamente difundida, esclarecendo que gênero não é uma construção social imposta a uma condição previamente determinada (o sexo), na medida em que o sexo, ele mesmo, não é estático. Assim, gênero seria um efeito performático que permite a elaboração e identificação de uma trajetória sexuada, a qual adquire solidez em função de reiteração de normas reguladoras que determinam os sistemas sexo-gênero. Ela argumenta, portanto, que as identidades são performativas, ou seja, são produzidas mediante reiterações pragmáticas de convenções sociais determinadas, adquirindo, assim, o efeito da estabilidade por meio desta repetição.

Vale frisar que as normas reguladoras determinantes dos sistemas sexo-gênero derivam, na modernidade, da matriz heterossexual constituída tanto pela dominação masculina como pela exclusão da homossexualidade. A heteronormatividade, ou seja, o modelo dos dois sexos, funda-se essencialmente, em um binarismo de sexo-gênero, que não cede espaço facilmente a outras construções identitárias.

Márcia Áran (ÁRAN, 2006) esclarece que

No entanto, se a produção repetida da normatização da sexualidade é necessária, isto significa que a materialização nunca é de fato completa, dado que os corpos nunca obedecem por completo às normas pelas quais sua materialidade é fabricada. Se os sistemas de sexo-gênero são construídos historicamente por meio de relações de poder, como ressalta Foucault e Butler, o gesto que instaura a norma produz também um domínio de corpos excluídos e abjetos, os quais servem de fronteira ou de limite de intelegibilidade. Várias manifestações das sexualidades são, desta forma, consideradas ininteligíveis, irreconhecíveis e inviáveis.

Assim, é possível reconhecer o sexo e o gênero masculinos e femininos a partir da performatividade assumida pelo indivíduo. Desta forma, o reconhecimento de alguém como homem ou mulher, como sujeito de gênero e sexualidade, significa nomeá-b tomando por referência as marcas distintivas de uma cultura, com a atribuição de direito e deveres, privilégios e desvantagens. Assim, como o gênero é performático, normas regulatórias de gênero e sexualidade precisam ser reiteradas e refeitas a fim de construir a materialidade dos corpos e garantir legitimidade aos sujeitos para além do reducionismo do determinismo biológico e da cisnormatividade, e sua incapacidade em dar respostas efetivas à realidade social 
Considerando o gênero como um elemento performático, o gênero como qual a pessoa se identifica (identidade de gênero) e, consequentemente, performa, ou seja, desempenha em seus papéis sociais deve ser reconhecido, afastando o paradigma reduzido da cisnormatividade, que domina os sistemas na atualidade.

Pode-se afirmar, portanto, que:

A desnaturalização do sexo biológico pode promover o questionamento da divisão binária da sociedade com seus efeitos de apropriação e dominação (...) Claro que Foucault não queria, com isso, afirmar que nós não nascemos com um aparelho genital dado, mas sim mostrar como o poder de práticas discursivas poderosas cria $\mathrm{o}$ corpo ao anunciá-lo sexuado, ao fazer de sua constituição biológica um fator "naturaP' que carrega características específicas e torna indiscutível a divisão dos seres humanos em dois blocos distintos.(SOUZA)

Com base na ideia de que o gênero é elemento performático da personalidade e desvinculado, portanto, de qualquer patologização, o acesso ao Processo Transexualizador deve estar desvinculado de diagnóstico de transtorno de identidade de gênero. A partir da ideia de que o acesso à saúde é universal, o acesso ao Processo Transexualizador deve ser acessível a todas as pessoas que não se sentem adaptadas ao seu sexo anatômico.

A vinculação predominante entre medicina e transexualidade apresenta aspectos que, contraditoriamente, acabam por prejudicar a pessoa transexual. Não se está negando aqui a importância da atuação da medicina em prol da saúde da pessoa transexual que, assim desejando, pode ter acesso a tratamentos oferecidos pelo Sistema Único de Saúde com vistas a encontrar um maior conforto físico e psicológico. No entanto, é fundamental atentar para o fato de que a necessidade de se definir o diagnóstico de uma patologia psiquiátrica para se ter acesso ao Processo Transexualizador é negar a integralidade do acesso à saúde.

Márcia Áran explica:

Ao conversar com homens e mulheres transexuais, conviver com eles e elas, no movimento social ou mesmo a partir da minha experiência clínica, pude perceber que estas pessoas têm várias experiências de construção de gênero e existem várias formas de subjetivação da transexualidade. Na minha opinião, não tem nada que justifique definir a transexualidade como uma patologia, nem mesmo como uma estrutura psíquica. É uma 
experiência de desacordo entre sexo e gênero que pode se manifestar de diversas formas. Isto não quer dizer que as pessoas trans, assim como qualquer outra pessoa, não possa manifestar uma forma de sofrimento psíquico, principalmente em função da experiência de exclusão social, de discriminação e muitas vezes de injúria e violência, e não possa necessitar ou desejar realizar uma psicoterapia ou um tratamento psiquiátrico ${ }^{2}$.

Diante, portanto, do reconhecimento de que a transexualidade é uma das muitas experiências de construção de gênero, não se sustenta a obrigatoriedade de a pessoa transexual se submeter ao processo transexualizador, quiçá à cirurgia de redesignação sexual para, então, ser considerada pessoa transexual e, consequentemente, ter seus direitos garantidos. Ademais, é preciso registrar que o descaso com a saúde pública dirigida às pessoas transexuais que desejam se submeter à cirurgia é enorme. Levantamento realizado pela TRansRevolução, grupo de apoio às pessoas transgêneras, revela que no Estado de São Paulo existe uma fila de 3.200 pessoas à espera da cirurgia de transgenitalização pelo Sistema Único de Saúde, sendo apenas uma cirurgia realizada a cada mês. A situação no Estado do Rio de Janeiro é ainda pior, pois o setor do único hospital do Estado habilitado a realizar a cirurgia, o Hospital Universitário Pedro Ernesto, está fechado desde $2013^{3}$.

Impende esclarecer que está em curso Ação Direta de Inconstitucionalidade $\mathrm{n}^{\circ}$ 4275/2009, que busca que seja proferida decisão de interpretação conforme à Constituição do artigo 58 da Lei 6015/73, reconhecendo o direito dos transexuais, que assim o desejarem, à substituição de prenome e sexo no registro civil, independentemente da cirurgia de transgenitalização, em respeito aos princípios da Dignidade da Pessoa Humana, da Liberdade e da Privacidade.

Espera-se que esta ação seja julgada procedente, mas até que isto ocorra a pessoa transexual não redesignada resta em posição vulnerável, na medida em que os juízes e tribunais tendem a exigir a realização da cirurgia de redesignação sexual para autorizar a alteração do prenome e designativo de sexo. Outros, mais conservadores, até mesmo diante da cirurgia de transgenitalização não autorizam ${ }^{4}$. Por esta razão, o Superior Tribunal de Justiça,

\footnotetext{
${ }^{2}$ Disponível em http://www.clam.org.br/publique/cgi/cgilua.exe/sys/start.htm?infoid=6250\&sid=7. Acesso em: 11.03 .16

${ }^{3}$ Nome social é direi to da população trans exual. In: Revista Praxis. Ano VII. № 81. Janeiro/Fevereiro 2015.

4 EMENTA: RETIFICAÇÃO NO REGISTRO CIVIL. MUDANÇA DE NOME E DE SEXO. IMPOSSIBILIDADE. SENTENÇA MANTIDA. O homem que almeja transmudar-se em mulher, submetendo-se a cirurgia plástica reparadora,
} 
no julgamento do Recurso Especial $n^{\circ}$ 1.008.398-SP, de relatoria da Ministra Nancy Andrighi decidiu que "vetar a alteração do prenome do transexual redesignado corresponderia a mantêlo em uma insustentável posição de angústia, incerteza e conflitos, que inegavelmente atinge a dignidade da pessoa humana assegurada pela Constituição Federal",5

Fundamental diante do exposto acima, a despatologização da transexualidade. A partir da despatologização, não mais se submeterá a alteração do registro civil à cirurgia de redesignação sexual, importando tão-somente, a identidade de gênero autopercebida pela pessoa transexual, em respeito à sua autonomia como sujeito de direitos.

O documento que prevê os Princípios de Yogyakarta $^{6}$ define a identidade de gênero como

a vivência interna e individual do gênero tal como cada pessoa o sente, a qual pode corresponder ou não com o sexo atribuído após o nascimento, incluindo a vivência pessoal do corpo. O exercício do direito à identidade de gênero pode envolver a modificação da aparência ou da função corporal através de meios farmacológicos, cirúrgicos ou de outra índole, desde que isso seja livremente escolhido. Também inclui outras expressões de gênero, como a vestimenta, os modos e a fala.

\subsection{A FUNDAMENTALIDADE DO DIREITO AO NOME}

Fundamental para o exercício pleno da identidade de gênero autopercebida é o nome. O nome social, conceituado pelo Ministério da Educação como "aquele pelo qual essas pessoas se identificam e são identificadas pela sociedade" ${ }^{, 7}$, exerce papel fundamental no exercício da cidadania pelo indivíduo. Isto ocorre porque a partir do momento em que a

extirpando os órgãos genitais, adquire uma "genitália" com similitude externa ao órgão feminino, não faz jus à retificação de nome e de sexo porque não é a medicina que decide o sexo e sim a natureza. Se o requerente ostenta aparência feminina, incompatível coma sua condição de homem, haverá de assumir as conseqüências, porque a opção foi dele. O Judiciário, ainda que em procedimento de jurisdição voluntarie, não pode acolher tal pretensão, eis que a extração do pênis e a abertura de uma cavidade similar a uma neovagina não têm o condão de fazer do homem, mulher. Quem nasce homem ou mulher, morre como nasceu. Genitália similar não é autêntica. Autêntico é o homem ser do sexo masculino e a mul her do feminino, a toda evidência. (Apelação Cível no 1993.001.06617, Oitava Câmara Cível, Tribunal de Justiça do Rio de Janeiro, julga do em 18/03/1997).

${ }^{5}$ Disponível em: https://ww2.sti.jus.br/processo/revista/documento/mediado/?componente=ATC\&sequencial=6666092\&num registro=200702733605\&data=20091118\&tipo=5\&formato=PDF. Acesso em 14.03.16

${ }^{6}$ Princípios sobre a aplicação da legislação interna cional de direitos humanos em relação à orientação sexual e identidade de gênero. Disponível em: http://www.clam.org.br/pdf/principios de yogyakarta.pdf. Acesso em 15.03.16.

7 Disponível em: http://docslide.com.br/documents/portaria-no-1612-de-18-de-novembro-de-2011.html. Acesso em 14.03.16. 
pessoa transexual pode se identificar socialmente por um nome que reflete a sua aparência, ela se sente suficientemente confortável para abandonar a invisibilidade que caracteriza sua existência. A importância do nome social é tamanha que no âmbito federal, estadual e municipal, diversas entidades da Administração Pública Direta e instituições de ensino já editaram normas que garantem às pessoas travestis e transexuais o uso do "nome social". Este fenômeno normativo é reflexo da percepção pelo Estado de que a discordância entre vida real e documentação oficial viola a dignidade da pessoa humana.

O nome social, no entanto, não é bastante em diversas situações da vida cotidiana, sendo necessária uma alteração no registro civil para que a documentação oficial da pessoa transexual coincida com a imagem que ela apresenta.

Sobre a importância do nome, insta colacionar os ensinamentos do professor Sílvio de Salvo Venosa (VENOSA, 2016, p. 209):

O nome é, portanto, uma forma de individualização do ser humano na sociedade, mesmo após a morte. Sua utilidade é tão notória que há exigência para que sejam atribuídos nomes a firmas, navios, aeronaves, ruas, praças, acidentes geográficos, cidades etc. O nome, afinal, é o substantivo que distingue as coisas que nos cercam e o nome da pessoa a distingue das demais, juntamente com os outros atributos da personalidade, dentro da sociedade. É pelo nome que a pessoa fica conhecida no seio da família e da comunidade em que vive. Trata-se da manifestação mais expressiva da personalidade.

Como é cediço, no Brasil, a retificação do registro civil a fim de alterar o prenome se admite em algumas poucas oportunidades, tais como aquela prevista no artigo 56 da Lei 6015/73 que estabelece que "o interessado, no primeiro ano após ter atingido a maioridade civil, poderá, pessoalmente ou por procurador bastante, alterar o nome, desde que não prejudique os apelidos de familia, averbando-se a alteração que será publicada pela imprensa.". No entanto, posterior alteração de nome somente será admitida por exceção e motivadamente, após audiência do Ministério Público e por sentença do juiz a que estiver sujeito o registro, nos termos do artigo 57 da referida lei

Sendo, portanto, atributo basilar da personalidade, o direito ao nome civil ostenta todas as características próprias dos direitos da personalidade: é absoluto, obrigatório, indisponível, imprescritível, inalienável, incessível, inexpropriável, irrenunciável, 
intransmissível (FARIAS, ROSENVALD, 2007, p. 171). Paralelamente a estes atributos do nome, encontra-se a pretensão da imutabilidade do mesmo, especialmente do prenome, como se infere da regra constante do artigo 58 da Lei 6015/73. Mas esta mesma regra admite a possibilidade de alteração do prenome da pessoa transexual, pois determina que "o prenome será definitivo, admitindo-se, todavia, a sua substituição por apelidos públicos notórios. ". Considerando ser o nome social um apelido público notório, pois é por ele que a pessoa transexual se identifica e se individualiza no meio social, reconhece-se nesta norma a autoriação necessária para alteração do prenome da pessoa transexual No entanto, esta possibilidade deve ser judicializada e também participada ao Ministério Público, por força do exposto no artigo 57 da referida lei

Desta forma, a alteração de prenome, com exceção daquela admitida após um ano de atingida a maioridade civil, submete-se não apenas ao Poder Judiciário, mas à discricionariedade do Poder Judiciário, haja vista a exigência legal, prevista no artigo 57 da Lei de Registros Públicos, de se motivar o pedido, motivação esta que pode ou não ser considerada, pelo julgador, razão suficiente para o deferimento da retificação.

Nas palavras de Carlos Santiago Nino (NINO, 1989, pp 204-205):

(...) sendo valiosa a livre eleição individual de planos de vida e a adoção de ideais de excelência humana, o Estado (e os demais indivíduos) não devem interferir nesta eleição ou adoção, limitando-se a desenhar instituições que facilitem a persecução individual destes planos de vida e a satisfação dos ideais de virtude que cada um sustente e impedindo a interferência mútua no curso de tal persecução.

Ensina o mestre Pontes de Miranda (MIRANDA, 2000) que: "A Constituição de 1988, (...) tinha, coerentemente, de assegurar o nome individual, posto que não precisasse dizê-lo explicitamente: o direito ao nome, direito de personalidade, é um dos direitos que se incluem no art. $5^{\circ}, \S 2^{\circ}$.”. O parágrafo $2^{\circ}$ do mencionado art. $5^{\circ}$ trata do Princípio da Abrangência, na medida em que estabelece que: "Os direitos e garantias expressos nesta Constituição não excluem outros decorrentes do regime e dos princípios por ela adotados, ou dos tratados internacio nais em que a República Federativa do Brasil seja parte".

Considerando ser o direito ao nome um direito da personalidade e, portanto, direito fundamental, não se pode admitir submetê-lo à discricionariedade do Poder Judiciário, pois 
isto significaria aceitar a possibilidade de o mesmo ser recusado ao seu titular. Não se pode negar que os direitos da personalidade são desdobramentos do princípio da dignidade da pessoa humana, já esta só é respeitada na medida em que o são os direitos da personalidade.

Não se pode deixar de reconhecer o progresso constante do texto do projeto de lei $\mathrm{n}^{\circ}$ $5.002 / 2013$, apelidado de Projeto de Lei João W. Nery ${ }^{8}$ que prevê, em seu artigo $1^{\circ}$, que:

Toda pessoa tem direito:

I - ao reconhecimento de sua identidade de gênero;

II - ao livre desenvolvimento de sua pessoa conforme sua identidade de gênero;

III - a ser tratada de acordo com sua identidade de gênero e, em particular, a ser identificada dessa maneira nos instrumentos que acreditem sua identidade pessoal a respeito do/s prenome/s, da imagem e do sexo com que é registrada neles.

Além disso, em seu artigo $4^{\circ}$ determina que:

Toda pessoa que solicitar a retificação registral de sexo e a mudança do prenome e da imagem, em virtude da presente lei, deverá observar os seguintes requisitos:

I - ser maior de dezoito (18) anos;

II - apresentar ao cartório que corresponda uma solicitação escrita, na qual deverá manifestar que, de acordo com a presente lei, requer a retificação registral da certidão de nascimento e a emissão de uma nova carteira de identidade, conservando o número original;

III - expressar o/s novo/s prenome/s escolhido/s para que sejam inscritos.

Parágrafo único:

Em nenhum caso serão requisitos para alteração do prenome:

I - intervenção cirúrgica de transexualização total ou parcial;

II - terapias hormonais;

III - qualquer outro tipo de tratamento ou diagnóstico psicológico ou médico;

IV - autorzação judicial.

\footnotetext{
${ }^{8}$ João W. Nery é um homem transexual que ficou conhecido por seus dois livros autobiográficos: Erro de Pessoa - Joana ou João, de 1984, e Viagem Solitária -Memórias de um Transexual 30 anos depois, de 2011.
} 


\subsection{O RESPEITO À AUTONOMIA PRIVADA DA PESSOA TRANSEXUAL}

A possibilidade de modificação do prenome no registro civil sem necessidade de autorzação judicial representa o grau máximo de respeito à autonomia privada da pessoa transexual e, em consequência, à sua liberdade como titular de direitos e deveres. Considerando que a adequação do registro civil à vida real e à imagem da pessoa representa a possibilidade de se tornar visível, em consonância com as normas constitucionais de respeito à dignidade da pessoa humana, pois a ninguém é merecido submeter-se a privações e humilhações públicas por qualquer motivo, não faz sentido a manutenção da exigência de que esta adequação do registro se submeta à discricionariedade judicial.

Daniel Sarmento (SARMENTO, 2006, p. 154) neste sentido, explica que:

(...) a autonomia privada (...) significa o poder do sujeito de auto-regulamentar seus próprios interesses, (...), e tem como matriz a concepção de ser humano como agente moral dotado de razão, capaz de decidir o que é bom ou ruim para si, e que deve ter liberdade para guiar-se de acordo com estas escolhas, desde que elas não perturbem os direitos de terceiros nem violem outros valores relevantes da comunidade. Ela importa o reconhecimento de que cabe a cada pessoa, e não ao Estado ou a qualquer outra instituição pública ou privada, o poder de decidir os rumos de sua própria vida, desde que isto não implique lesão a direitos alheios. Esta é uma ideia essencial ao princípio da dignidade da pessoa humana (...)"

Assim, além de a autonomia ser instrumental da democracia, pois apenas dotada de autonomia a pessoa é capaz de exercer plenamente sua cidadania em seus aspectos civil, social e políico, ela também é apanágio da dignidade da pessoa humana. Vale lembrar que cidadania, no sentido conferido por Thomas H. Marshall (MARSHALL, 1967, p. 76), e adotado nesta oportunidade, "é um status concedido àqueles que são membros integrais de uma comunidade. Todos aqueles que possuem o status são iguais com respeito aos direitos e obrigações pertinentes ao status. ".

A provocação que ora se coloca é: uma pessoa privada de ostentar documentos com nome e sexo coincidentes com sua imagem pode ser membro integral da comunidade? É tratada com respeito? É livre? É igual? Sem dúvida, a resposta é negativa a todas estas perguntas.

Luiza Cassemiro (CASSEMIRO) explica que 
A incompreensão sobre o que venha a ser identidade de gênero (seu devido valor na sexualidade humana e suas possíveis expressões a partir de seu estabelecimento) e sobre a sugnificação vivencial da transexualdiade $\mathrm{e}$ travestidade, tem contribuído para violentos processos de exclusão social dessas pessoas, expressos por exemplo nas problemáticas relacionais e familiares; na evasão escolar e baixa escolaridade; no frequente despreparo técnico e profissional; na discriminação no mercado de trabalho; na vulnerabilização e nas violências, tanto social quanto institucional.

Não se quer aqui, contudo, defender a ideia de uma autonomia privada absoluta. Por óbvio uma autonomia privada absoluta seria incompatível com o regime democrático que possibilita a coexistência pacífica de várias concepções de vida diferentes. Como bem explicou Daniel Sarmento (SARMENTO, 2006, p. 155):

(...) essa autonomia privada não é absoluta, pois tem de ser conciliada, em primeiro lugar, com o direito das outras pessoas a uma idêntica quota de liberdade, e, além disso, com outros valores igualmente caros ao Estado Democrático de Direito, como a autonomia pública (democracia), a igualdade, a solidariedade e a segurança.

Assim, por um lado, é esperado que o Estado restrinja a autonomia privada em algumas circunstâncias, seja por algum bem individual específico, seja pelo bem comum Em uma democracia, estas intervenções do Estado na autonomia privada se fazem por meio de lei. Mas, por outro lado, não se pode ignorar que, em uma democracia, há limites para a própria lei, de modo que esta não pode violar dimensões da autonomia privada que, em razão de sua relevância, afetam a própria dignidade da pessoa (SARMENTO, 2006, p. 155-156).

$\mathrm{O}$ direito e o dever de ter um nome surge da necessidade imperiosa de se individualizar uma pessoa no meio social Cristiano Chaves e Nelson Rosenvald (FARIAS, ROSENVALD, 2007, p. 170) explicam que "o nome civil é o sinal exterior pelo qual são reconhecidas e designadas as pessoas, no seio familiar e social Enfim, é o elemento designativo da pessoa."

A regra da imutabilidade - ainda que relativa - do nome surgiu, principalmente, com o objetivo de proteger interesses econômicos e financeiros de terceiros que poderiam ser potencialmente afetados com a alteração do prenome da pessoa. No entanto, é preciso atentar para o fato de que estes interesses são disponíveis, ao passo que o interesse do indivíduo em 
alterar seu prenome reflete diretamente na sua concepção como pessoa e na sua cidadania. Neste sentido, Roxana Borges (BORGES, 2007, p. 223-224) esclarece:

(...) a ratio que fundamenta a regra da imutabilidade do nome não está, historicamente, ligada à proteção dos direitos da personalidade, mas à proteção de interesses (legítimos) de terceiros, o que, estranhamente, não se coaduna com os fundamentos, nem com as finalidades dos direitos de personalidade. (...) Mais do que ser um elemento que integra o estado da pessoa, o direito ao nome é um direito de personalidade, e, assim considerado, volta- se mais aos interesses da própria pessoa titular do nome do que aos interesses de terceiros. Aí reside a possibilidade de exercício de certa autonomia jurídica sobre o direito ao nome.

Reconhecer à pessoa transexual autonomia para alterar seu prenome diretamente no registro civil, sem necessidade de submeter esta pretensão ao Poder Judiciário, não representa risco aos direitos de terceiros, na medida em que é possível fazer constar no livro do Cartório do Registro Civil, por meio de averbação, a alteração ocorrida, sendo possível, portanto, responsabilizar a pessoa por qualquer obrigação jurídica pendente que esta possua. Além disso, certidões de nascimento de inteiro teor, nas quais constam as averbações realizadas no registro, podem ser expedidas a pedido do próprio interessado ou por requisição judicial. (VIEIRA, 2012, p. 185).

\subsection{CONCLUSÃO}

Mostra-se de enorme relevância refletir a respeito da vulnerabilidade social e jurídica da população de pessoas transexuais. Para isso faz-se necessário demonstrar a posição marginal que estas pessoas ocupam na sociedade, em razão do estigma a que são continuamente submetidas, impedindo o exercício pleno da cidadania e o livre desenvolvimento de sua personalidade. Sem dúvida, uma das razões deste estigma e consequente discriminação social reside na falta de correspondência entre a imagem e o nome civil da pessoa transexual. Em busca de uma política inclusiva da diferença, é necessário que se faça uma interpretação conforme à Constituição tendo por objeto o artigo 58 da ki 6.015/73 (Lei de Registros Públicos) para, em respeito à dignidade da pessoa humana, à cidadania, à autonomia privada, à liberdade e à igualdade, dispense-se a exigência de autorização judicial da possibilidade alteração do registro civil da pessoa transexual 
A noção de igualdade, defendida no Estado Democrático de Direito, não se resume a sua dimensão formal, na medida em que a sua dimensão material é a verdadeira garantidora da justiça. Em uma sociedade que prima pela integração social de todas as pessoas, é imperioso priorzar a igualdade real entre as pessoas, ainda que seja necessário alterar paradigmas estruturais de poder existentes. A concepção de uma sociedade binária, que exclui as pessoas que confrontam a heteronormatividade em todas as suas concepções, não promove a construção de uma sociedade livre, justa e solidária, objetivo fundamental do projeto republicano brasileiro.

\section{REFERÊNCIAS BIBLIOGRÁFICAS}

ARAN, Márcia. A transexualidade e a gramática normativa do sistema sexo-gênero. Ágora (Rio J.) [online]. 2006, vol9, n.1, pp. 49-63. ISSN 1516-1498.

BENTO, Berenice; PELÚCIO, Larissa. Despatologização do gênero: a politização das identidades abjetas. In: Revista Estudos Feministas. Disponível em: http://dx.doi.org/10.1590/S0104-026X2012000200017. Acesso em 10.03.16

BORGES, Roxana Cardoso Brasileiro. Direitos de Personalidade e Autonomia Privada. São Paulo: Saraiva, 2007.

BUTLER, Judith. Cuerpos que importan. Sobre los limites materials y discursivos del "sexo". Buenos Aires: Paidós, 2002, p. 18.

BUTLER, Judith. 2003. Problemas de gênero: feminismo e subversão da identidade. Rio de Janeiro: Civilização Brasileira, p. 18.

CASSEMIRO, Luiza Carla. Tenho o direito de seramapô: as trajetórias de travestis e transexuais face à implementação das políticas públicas de assistência social e saúde. Disponível em: http://www.maxwell.vrac.puc-rio.br. Acesso ems 10 jun 2015.

CASTEL, Pierre-Henri. Algumas reflexões para estabelecer a cronologia do "fenômeno transexual" (1910-1995). Rev. bras. Hist., São Paulo , v. 21, n. 41, p. 77-111, 2001 . Available from <http $/ / \mathrm{www}$.scielo.br/scielo.php?script=sci_arttext\&pid=S0102$01882001000200005 \& \operatorname{lng}=$ en $\& n r m=$ iso $>$. access on 13 July 2015. http://dx.doi.org/10.1590/S0102-01882001000200005.

EKINS R., King D. (2001) Pioneers of Transgendering: The Popular Sexology of David O. Cauldwell. Disponível em: http://www.symposion.com/ijt/cauldwell/cauldwell_01.htm. Acesso em 10.03.16

FARIAS, Cristiano Chaves de; ROSENVALD, Nelson. Direito Civil: Teoria Geral Rio de Janeiro: Lumen Juris, 2007.

FOUCAULT, Michel. História da Sexualidade 1: a vontade de saber. Rio de Janeiro: Paz e Terra, 2015, pp. 07-18. 
MARSHALL, Thomas Humprey. Cidadania, classe social e status. Rio de Janeiro: Zahar Editores, 1967.

MIRANDA. Pontes de, atualizada por ALVES, Vilson Rodrigues. Tratado de Direito

Privado. Parte Especial, Tomo 7. Rio de Janeiro, Campinas, SP: Bookseller, 2000.

NINO, Carlos Santiago. Ética y Derechos Humanos. Buenos Aires: Editorial Astrea, 1989, p. 204-205.

VENOSA, Sílvio de Salvo. Direito Civil. Parte Geral 16a ed., São Paub: Atlas, 2016, p. 209

VIEIRA, Tereza Rodrigues. Nome e Sexo: mudanças no registro civil São Paulo: Atlas, 2012.

SARMENTO, Daniel. Direitos Fundamentais e Relações Privadas. Rio de Janeiro: Lumen Juris, 2006.

SOUZA, Alberto Carneiro Barbosa de. Se ele é artilheiro, eu também quero sair do banco: um estudo sobre a co-parentalidade homossexual. Disponível em: www.maxwell.vrac.pucrio.br/11727/11727_3.PDF. Acesso em 30 jun 2015. 